\title{
Magnetic Solid-Phase Extraction Based on Poly 4-Vinyl Pyridine for HPLC-FLD Analysis of Naproxen in Urine Samples
}

\author{
Karen A. Escamilla-Lara ${ }^{1}$, Ana C. Heredia ${ }^{2}$, Araceli Peña-Alvarez ${ }^{2}$, Israel S. Ibarra ${ }^{1}$, \\ Enrique Barrado ${ }^{3}$ and Jose A. Rodriguez ${ }^{1, *}$ (D)
}

1 Area Academica de Quimica, Universidad Autonoma del Estado de Hidalgo, Carretera Pachuca-Tulancingo Km. 4.5, Mineral de la Reforma 42184, HGO, Mexico; qescamilla04@gmail.com (K.A.E.-L.); israel_ibarra@uaeh.edu.mx (I.S.I.)

2 Facultad de Quimica, Departamento de Quimica Analitica, Universidad Nacional Autonoma de Mexico, Ciudad de Mexico 04510, Mexico; hera21.ach@gmail.com (A.C.H.); arpeal@unam.mx (A.P.-A.)

3 Department of Analytical Chemistry, Facultad de Ciencias, Universidad de Valladolid, Campus Miguel Delibes, Calle Paseo de Belen, 7, 47011 Valladolid, Spain; ebarrado@qa.uva.es

* Correspondence: josear@uaeh.edu.mx; Tel.: +52-771717200 (ext. 2202)

Academic Editors: Alireza Ghiasvand, Joselito P. Quirino and Yunlei Xianyu check for Received: 3 June 2020; Accepted: 24 June 2020; Published: 25 June 2020

\begin{abstract}
A magnetic solid phase extraction technique followed by liquid chromatography with a fluorescence detector for naproxen analysis in human urine samples was developed. The method includes the extraction of naproxen with a magnetic solid synthetized with magnetite and poly 4 -vinylpriridine, followed by the magnetic separation of the solid phase and desorption of the analyte with methanol. Under optimal conditions, the linear range of the calibration curve was $0.05-0.60 \mu \mathrm{g}$ $\mathrm{L}^{-1}$, with a limit of detection of $0.02 \mu \mathrm{g} \mathrm{L} \mathrm{L}^{-1}$. In all cases values of repeatability were lower than $5.0 \%$ with recoveries of $99.4 \pm 1.3 \%$. Precision and accuracy values are adequate for naproxen $(\mathrm{Npx})$ analysis in urine samples.
\end{abstract}

Keywords: MSPE; HPLC-FLD; 4-vynilpiridine; naproxen

\section{Introduction}

Naproxen (Npx) is a pharmaceutical compound that belongs to the group of non-steroid anti-inflammatory (AINEs). Its properties allow it to act as anti-inflammatory, analgesic, and antipyretic [1], it is used for the treatment of rheumatoid arthritis, osteoarthritis, acute traumatic lesion and prophylactic treatment [2]. Structurally it is a derivative of propionic acid (Figure 1), shows values of $\log \mathrm{P} 3.18$ and pKa 4.2. Its main function is to inhibit the production of cyclooxygenase and reduce the concentration of prostaglandin in several biological fluids and tissues [3].<smiles>COc1ccc2cc([C@@H](C)C(=O)O)ccc2c1</smiles>

Figure 1. Naproxen (Npx) chemical structure. 
There are different techniques described to quantify Npx, such as: UV-Vis spectroscopy [4], gas chromatography [5], liquid chromatography [6], and capillary electrophoresis [7]. The aforementioned techniques require a previous sample preparation step because of pharmaceutical compound is found in concentrations of $\mu \mathrm{g} \mathrm{L}^{-1}$ or ng L ${ }^{-1}$ in different analytical matrices $[8,9]$.

Solid phase extraction (SPE), using octadecylsilane (C18) or polymeric cartridges ( $N$-vinylpyrrolidone and divinylbenzene) has been preferred for the preconcentration process of Npx $[10,11]$. Solid phase microextraction techniques were also proposed in order to decrease the amount of solvents and its limits of detection achieved when it is coupled to sensitive instrumental techniques [12,13]. Another alternative is dispersive solid phase extraction, d-SPE [14], which it is characterized by the use of adsorbent materials in nanometric scale improving the contact between the adsorbent surface and the analyte [15]. The extraction phase should be modified to improve selectivity, however, nanomaterial separation is complex. The incorporation of a paramagnetic phase to the adsorbent facilitates the separation using an external magnetic field, avoiding filtration or centrifugation steps. This d-SPE variation is co-called magnetic solid phase extraction (MSPE) [16]. The adsorbents employed are commonly composed by a magnetic core, usually magnetite $\left(\mathrm{Fe}_{3} \mathrm{O}_{4}\right)$, covered by a shell which promoted selectivity in the extraction process and protect the magnetite from degrading. Some solids proposed for Npx analysis includes a shell phase of, carbon (graphene and carbon nanotubes), silica, and polymer [17-23].

Organic polymers have shown to be a viable alternative to protect magnetic core, furthermore they allows the incorporation of a large variety of functional groups in the surface [24]. Npx is an acid molecule and therefore the presence of an aromatic monomer of basic nature promotes the adsorbent-analyte interaction via acid-base or $\pi-\pi$ interactions $[25,26]$. This work proposed the synthesis of a magnetic solid based on poly-4-vinyl pyridine (P4-VP).

\section{Results and Discussion}

\subsection{Chemical Characterization of Magnetics Solids}

The diffraction spectra in all samples show a similar profile, Figure 2a shows the X-ray diffraction pattern for the magnetic solid C (see Section 3.3). A wide peak at small angles, around $15^{\circ}$ is related to the presence of amorphous polymeric material. A crystalline phase is identified at angles $20: 30.1^{\circ}$, $35.5^{\circ}, 43.1^{\circ}, 53.4^{\circ}$, and $62.6^{\circ}$, which corresponds to $\mathrm{Fe}_{3} \mathrm{O}_{4}$ [27]. The FTIR analysis (Figure 2b), shows a vibration band characteristic of the Fe-O bond at $571 \mathrm{~cm}^{-1}$, the signals between $3250-3750 \mathrm{~cm}^{-1}$ belong the stretching of the $\mathrm{O}-\mathrm{H}$ bond [28], at $2960 \mathrm{~cm}^{-1}$ the vibration of $-\mathrm{CH}_{2-},-\mathrm{CH}_{3}$ is observed, around of $1730 \mathrm{~cm}^{-1}$ is the band attributed to carbonyl group contained within the EGDMA and MA monomers, at $1654 \mathrm{~cm}^{-1}$ the vibration of the stretching of the $-\mathrm{C}=\mathrm{N}$ bond is observed, characteristic of the pyridine ring [29].
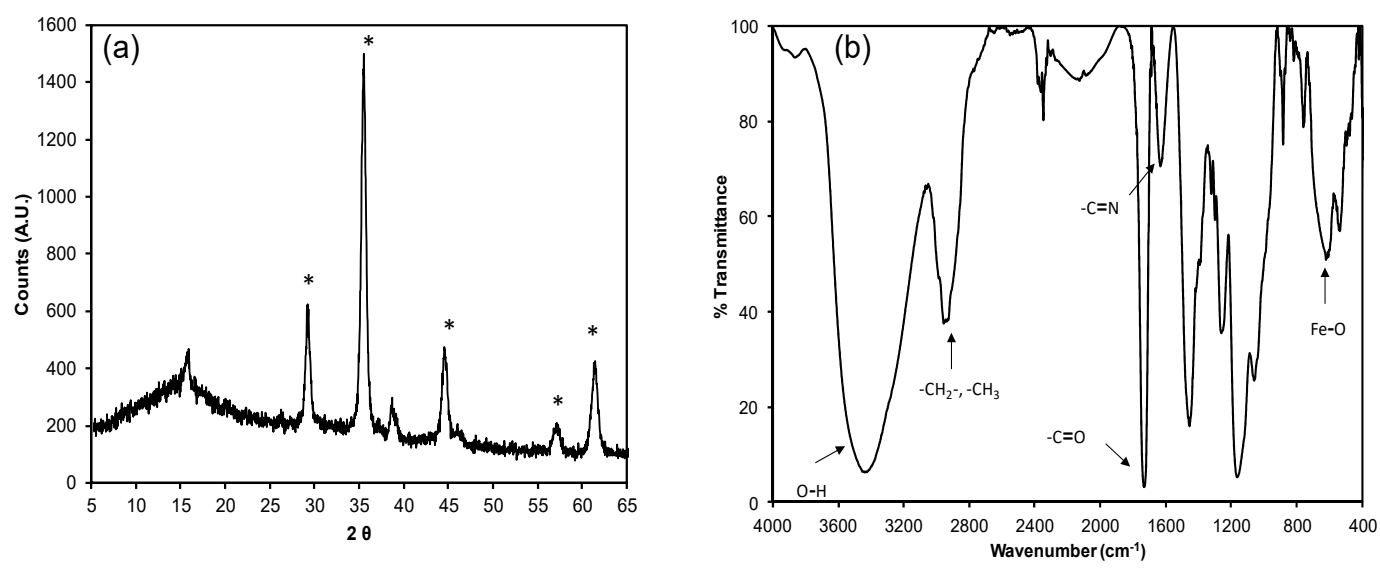

Figure 2. (a) Diffraction pattern for the magnetic solid and (b) FTIR spectrum for solid C. ${ }^{*} \mathrm{Fe}_{3} \mathrm{O}_{4}$. 


\subsection{Adsorption Capacity of Magnetic Solids}

Adsorption was evaluated a $\mathrm{pH}$ values of 2.0, 4.0, and 6.0, however, Npx was not retained at $\mathrm{pH}>4$.0. The Figure 3 shows the adsorption isotherms $($ at $\mathrm{pH}=2.0)$ for the three synthesized magnetic solids. The value of the affinity constant among magnetic solids is estimated and the analyte used in the scatchard graph adjusts to Equation (1), where [Npx-S] $\left(\mathrm{mmol} \mathrm{kg}^{-1}\right)$ corresponds to the Npx adsorpted on the solid and [Npx] $\left(\mathrm{mmol} \mathrm{L}^{-1}\right)$ is the concentration of the pharmaceutical compound in liquid phase after adsorption process. Data are adjusted to a straight line according to Equation (1) where Qmax is the maximum quantity of Npx that can be adsorbed and $\mathrm{Kd}$ is the affinity constant estimated from the slope $(-1 / \mathrm{Kd})$ for the equilibrium $\mathrm{Npx}-\mathrm{S} \leftrightarrows \mathrm{Npx}+\mathrm{S}$.

$$
\frac{[\mathrm{Npx}-\mathrm{S}]}{[\mathrm{Npx}]}=\frac{\mathrm{Q}_{\max }}{\mathrm{K}_{\mathrm{d}}}-\frac{[\mathrm{Npx}-\mathrm{S}]}{\mathrm{K}_{\mathrm{d}}}
$$

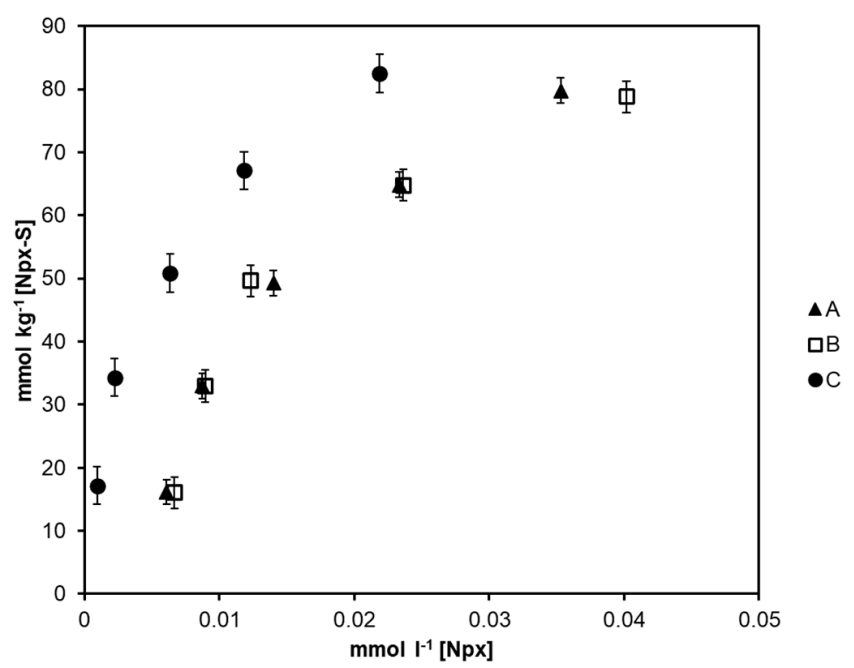

Figure 3. Adsorption isotherms for the three synthesized magnetic solids. Experimental conditions: room temperature, $\mathrm{pH}$ value of 2.0 (adjusted with $\mathrm{HCl}$ ) and contact time of $30 \mathrm{~min}$.

Table 1 shows the $\mathrm{Kd}$ values found, in all the cases the estimated value is located at the $1 \times 10^{-7}$ and $1 \times 10^{-4} \mathrm{M}$ interval, which is appropriate for the retention and elution processes [30]. From the three solids, $\mathrm{C}$ shows more affinity towards $\mathrm{Npx}$. The values estimated are congruent to the number of active groups determined (expressed as mmol HCl kg${ }^{-1}$ ). At low $\mathrm{pH}$ values, magnetite [31] and P4-VP [32] surfaces are positive charged, in consequence repulsion force favored the exposition of pyridinium group. In this sense, magnetite content is higher in the solid (C) and in consequence, an increment on active sites and analyte-solid affinity was observed. The results showed a moderate adsorption capacity because of the low molar ratio of 4-VP, however an increment on concentration of functional monomer produces solubility of P4-VP decreasing protection of magnetic core and adsorption capacity.

Table 1. Calculated parameters for the characterization of magnetic solids.

\begin{tabular}{cccc}
\hline Solid & Kd $\left(\times \mathbf{1 0}^{-\mathbf{6}} \mathbf{M}\right)$ & $\begin{array}{c}\text { Active Sites } \\
\left(\mathbf{m m o L ~ H} \mathbf{~ k g}^{-\mathbf{1}}\right)\end{array}$ & $\begin{array}{c}\text { Qmax } \\
\left(\mathbf{m m o L ~} \mathbf{~ g ~}^{-\mathbf{1}}\right)\end{array}$ \\
\hline A & $24.5 \pm 0.1$ & $700 \pm 3$ & $79.8 \pm 1.0$ \\
$\mathrm{~B}$ & $20.4 \pm 0.1$ & $500 \pm 2$ & $78.8 \pm 5.7$ \\
$\mathrm{C}$ & $3.5 \pm 0.1$ & $1200 \pm 4$ & $82.5 \pm 1.4$ \\
\hline
\end{tabular}




\subsection{Optimization of the MSPE Conditions}

A retention-elution process is affected by several variables. Taguchi experimental design was selected as a robust optimization method to evaluate the control variables involved on MSPE [33]. In the separation using MSPE, the output signal is maximizing the response (Area Npx/Area I.S). The control variables involved in the process are: composition of the magnetic solid, [NaCl] added (M), $\mathrm{pH}$ value, and methanol volume ( $\mathrm{mL}$ ) employed for elution [34]. Three levels for each factor were selected using an orthogonal matrix $\mathrm{L}_{9}\left(3^{4}\right)$. The tests were performed using a spiked urine sample $(50.0 \mu \mathrm{g} \mathrm{L}-1)$ of Npx. The design matrix and the results are shown in Table 2.

Table 2. Orthogonal matrix and its correspondent [Area Npx]/[Area SI] for each experiment.

\begin{tabular}{cccccc}
\hline Experiment & $\mathbf{S C}$ & $\mathbf{N a C l}(\mathbf{M})$ & $\mathbf{M V}(\mathbf{m L})$ & $\mathbf{p H}$ & [Area Npx]/[Area IS] \\
\hline 1 & $\mathrm{~A}$ & 0.5 & 1 & 1 & 0.97 \\
2 & $\mathrm{~A}$ & 1.0 & 2 & 2 & 0.56 \\
3 & $\mathrm{~A}$ & 1.5 & 3 & 3 & 1.58 \\
4 & $\mathrm{~B}$ & 0.5 & 2 & 3 & 0.98 \\
5 & $\mathrm{~B}$ & 1.0 & 3 & 1 & 0.82 \\
6 & $\mathrm{~B}$ & 1.5 & 1 & 2 & 4.90 \\
7 & $\mathrm{C}$ & 0.5 & 3 & 2 & 0.94 \\
8 & $\mathrm{C}$ & 1 & 1 & 3 & 2.15 \\
9 & $\mathrm{C}$ & 1.5 & 2 & 1 & 0.60 \\
\hline
\end{tabular}

SC-solid composition, MV-methanol volume.

Figure 4 shows the effect of the factors over the output variable, being the $\mathrm{pH}$ the factor with highest contribution to the system $(41.11 \%)$, followed by the methanol volume $(23.3 \%),[\mathrm{NaCl}]$ added (19.64\%), and finally the composition of the magnetic solid (15.99\%).

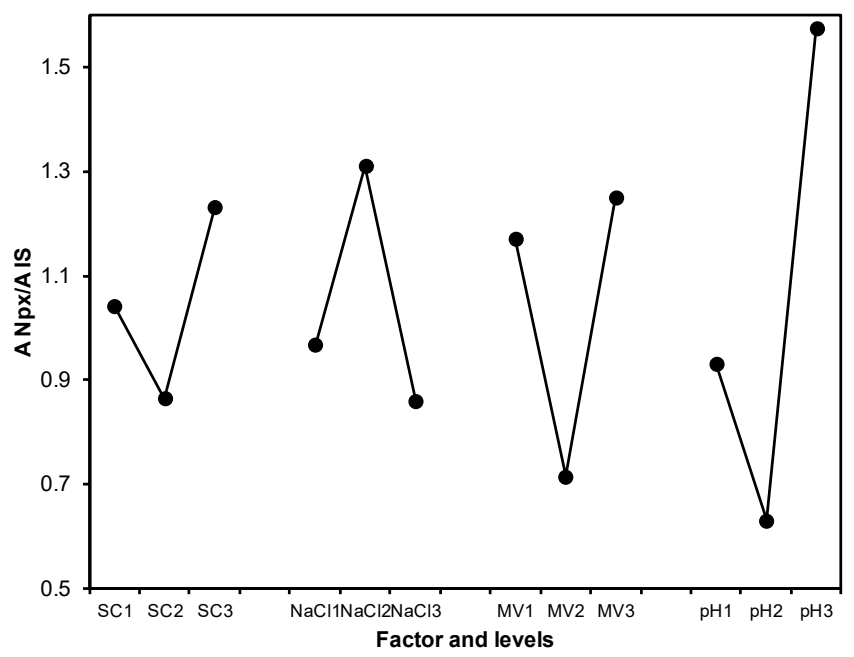

Figure 4. Effect of the control factors over the Npx extraction process.

Based on the adsorption results, it is confirmed that the most adequate solid is the solid C. Additionally, the magnetite concentration is higher which promotes a better recovering of the magnetic solid. An increase on the ionic force reduces the solubility of the hydrophobic compounds promoting the retention of the analyte on the extractive phase [35]. The results indicate that increase of $\mathrm{NaCl}$ concentration promotes $\mathrm{Npx}$ retention. However, when $[\mathrm{NaCl}]$ is employed $1.5 \mathrm{M}$ there is a competence between chlorine ions and the analyte during adsorption, affecting retention [36]. Since [NaCl] of $1.0 \mathrm{M}$ yielded higher signals, it was chosen as optimal concentration value.

Regarding the $\mathrm{pH}$ value, this variable is important in extraction processes of substances with acid-basic properties. The extraction of Npx is improved when the pharmaceutical compound is in its 
neutral form, adjustment of the $\mathrm{pH}$ value should be performed below the Npx pKa value. The optimal value found was $\mathrm{pH}=3.0, \mathrm{P} 4-\mathrm{VP}$ is positive charged (pyridinium cation) at this $\mathrm{pH}$ value. However, the multiple aromatic units covalently attached on the adsorbent can interact with planar aromatic analytes [37]. This result indicates that presence of naphthalene ring in naproxen structure increased interaction with P4-VP via $\pi-\pi$ interaction.

The elution solvent was selected considering the polarity (less polar than the analytical matrix) and the solubility of analyte. Several methodologies showed that methanol is adequate eluent for Npx because of solubility of the pharmaceutical compound and additionally it is a component of the mobile phase [38]. A volume of $3.0 \mathrm{~mL}$ of methanol was selected for Npx elution.

\subsection{Method Validation and Urine Samples Analysis}

Under the following opimal conditions: solid C, $\mathrm{NaCl}$ concentration $1.0 \mathrm{M}, \mathrm{pH}=3.0$, and $3.0 \mathrm{~mL}$ of methanol, it was constructed the calibration curve using urine spiked standards of 5.0, 10.0, 20.0, $30.0,40.0,50.0$, and $60.0 \mu \mathrm{g} \mathrm{L}^{-1}$ of $\mathrm{Npx}$. The calibration curve was adjusted to the following equation: $\mathrm{A}_{\mathrm{Npx}} / \mathrm{A}_{\mathrm{IS}}=14.868 \pm 0.75[\mathrm{Npx}] /[\mathrm{IS}]+0.0182 \pm 0.06\left(\mathrm{R}^{2}=0.99\right)$ with a linear range of $0.05-60.0 \mu \mathrm{g}$ $\mathrm{L}^{-1}$ Limit of detection and limit of quatification were calculated according to FDA criteria [39] as $3.3 \mathrm{~s}_{\mathrm{c}} / \mathrm{b} 1$ and $10 \mathrm{~s}_{\mathrm{c}} / \mathrm{b} 1$, where $\mathrm{s}_{\mathrm{c}}$ is the square root of the residual variance of the standard curve, and $\mathrm{b} 1$ is the analytical sensitivity. Limit of detection and limit of quatification were $0.02 \mu \mathrm{g} \mathrm{L}-1$ y $0.05 \mu \mathrm{g} \mathrm{L}^{-1}$, respectively. In order to validate the limit of quantification, a spiked urine sample $\left(0.05 \mu \mathrm{g} \mathrm{L}^{-1}\right)$ was analyzed in triplicate and the data obtained were: a mean recovery of $104.1 \%$ with precision of $6.9 \%$ (expressed as relative standard deviation, $n=3$ ). Figure 5 shows a chromatogram obtained for analysis of: blank urine sample (Figure 5a) and spiked with 0.05 (Figure 5b) and $35 \mu \mathrm{g} \mathrm{L}-1$ (Figure 5c) of Npx. Absolute recovery was evaluated by comparing the signal ratio obtained from the analysis of a Npx standard $\left(10.0 \mu \mathrm{g} \mathrm{L}^{-1}\right)$ prepared in urine and deionized water, by the proposed methodology. An absolute recovery value of $83.5 \%$ was obtained as a consequence of co-extraction of urine components.

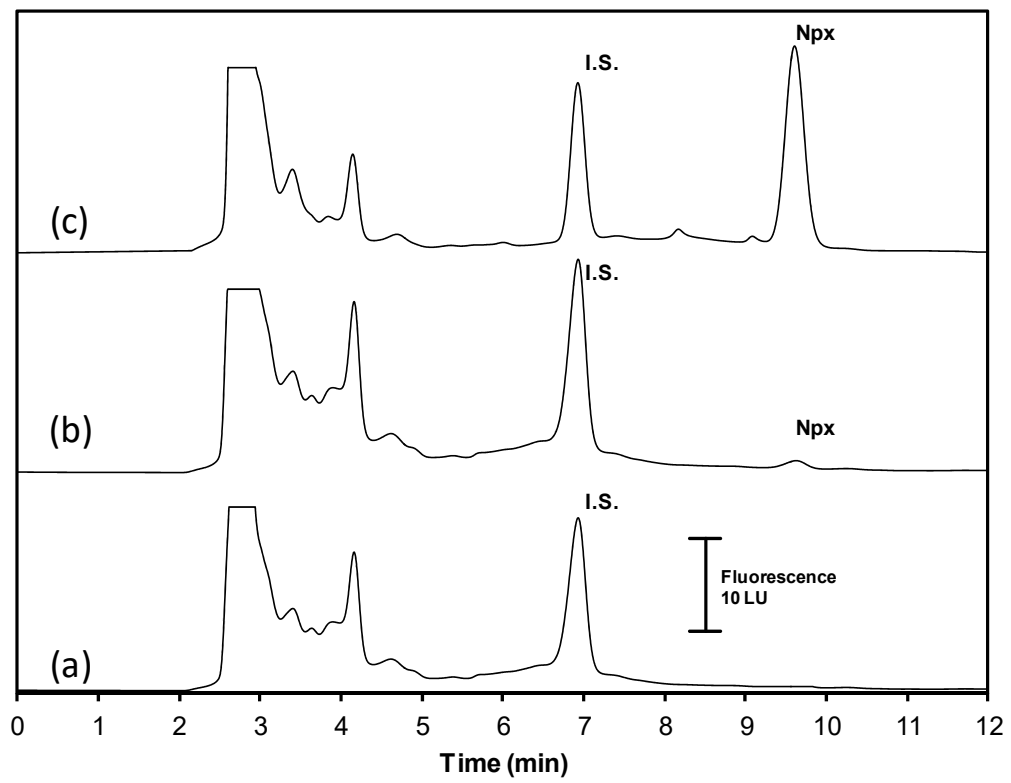

Figure 5. Chromatogram obtained from the analysis of an urine sample under optimal conditions.

(a) blank sample, (b) Npx $0.05 \mu \mathrm{g} \mathrm{L}{ }^{-1}$, (c) $\mathrm{Npx} 35 \mu \mathrm{g} \mathrm{L}-1$. Internal standard (I.S. $50 \mu \mathrm{g} \mathrm{L}^{-1}$ ).

Precision was evaluated in terms of within-day and between-days repeatability for calculated Npx concentration, determined by interpolation in calibration curve obtained with spiked urine standards. Results were expressed as relative standard deviation (\% RSD) obtained from the analysis of spiked urine samples $(n=3)$ with Npx concentrations of 5.0,30.0, and $50.0 \mu \mathrm{g} \mathrm{L} \mathrm{L}^{-1}$ during three days, 
in all cases the values were lower than 5.0\%. Accuracy of the proposed method was investigated by determining the recovery of Npx in spiked urine samples. Recovery was expressed as \% Recovery $=\left(100[\mathrm{Npx}]_{\text {calculated }}\right) /[\mathrm{Npx}]_{\text {added }}$. The results are summarized in Table 3 and indicate acceptable recovery factors.

Table 3. Npx concentration determined in spiked urine sample using the proposed method.

\begin{tabular}{|c|c|c|c|c|}
\hline $\begin{array}{l}{[\mathrm{Npx}]_{\text {added }}} \\
\left(\mu \mathrm{L} \mathrm{L}^{-1}\right)\end{array}$ & $\begin{array}{l}{[\mathrm{Npx}]_{\text {calculated }}} \\
\left(\mu \mathrm{g} \mathrm{L}^{-1}\right)\end{array}$ & $\begin{array}{c}\text { Repeatability, Within-Day } \\
(\% R S D, n=3)\end{array}$ & $\begin{array}{c}\text { Repeatability, Between-Days } \\
\text { (\%RSD, } n=3)\end{array}$ & $\%$ Recovery \\
\hline 5.0 & 4.9 & 2.2 & 3.7 & 98.0 \\
\hline 30.0 & 30.2 & 1.6 & 1.9 & 100.7 \\
\hline 50.0 & 49.7 & 1.5 & 2.1 & 99.4 \\
\hline
\end{tabular}

MSPE-HPLC-Fluorescence detection methodology was applied to analyze Npx in four different urine samples (two men and two 2 women), Npx concentration was determined by interpolation into the calibration line obtained with spiked urine samples. Initial concentrations were in the interval of 1.3-8.2 $\mu \mathrm{g} \mathrm{L}^{-1}$. In order to evaluate applicability, urine samples were spiked with 15 and $35 \mu \mathrm{g}$ $\mathrm{L}^{-1}$ of Npx and they were analyzed in triplicate. Results obtained are shown in Table 4, the average recovery was $98.6 \pm 1.6 \%$. Considering the differences in the matrix composition and the presence of creatinine, inorganic salts, urea, uric acid, the methodology proposed is useful for analysis of Npx in urine samples.

Table 4. Npx concentration determined in urine sample using the proposed method.

\begin{tabular}{|c|c|c|c|c|}
\hline Sample & $\begin{array}{l}{[\mathrm{Npx}]_{\mathrm{added}}} \\
\left(\mu \mathrm{g} \mathrm{L}^{-1}\right)\end{array}$ & $\begin{array}{c}{[\mathrm{Npx}]_{\text {calculated }}} \\
\left(\mu \mathrm{g} \mathrm{L}^{-1}, \% \mathrm{RSD}, n=3\right)\end{array}$ & $\begin{array}{l}{[\mathrm{Npx}]_{\text {total }}} \\
\left(\mu \mathrm{g} \mathrm{L}^{-1}\right)^{\mathrm{a}}\end{array}$ & $\%$ Recovery $^{b}$ \\
\hline \multirow[t]{3}{*}{ M1 } & & $8.2(1.9)$ & & \\
\hline & 15.0 & $22.1(1.7)$ & 23.2 & 95.3 \\
\hline & 35.0 & 42.7 (1.3) & 43.2 & 98.8 \\
\hline \multirow[t]{3}{*}{ M2 } & & $7.8(2.0)$ & & \\
\hline & 15.0 & $23.1(2.0)$ & 22.8 & 101.3 \\
\hline & 35.0 & $42.0(0.7)$ & 42.8 & 98.1 \\
\hline \multirow[t]{3}{*}{ W1 } & & $6.0(2.5)$ & & \\
\hline & 15.0 & $20.3(2.3)$ & 21.0 & 96.7 \\
\hline & 35.0 & $40.7(2.7)$ & 41.0 & 99.3 \\
\hline \multirow{3}{*}{ W2 } & & $1.3(4.6)$ & & \\
\hline & 15.0 & $16.4(1.9)$ & 16.3 & 100.6 \\
\hline & 35.0 & 35.7 (1.3) & 36.3 & 98.3 \\
\hline
\end{tabular}

Table 5 shows a comparison between the results obtained by the proposed method and others proposed for Npx determination in human urine. The proposed method has competitive limits of detection with the advantage of reducing the analysis time and decrease sample and eluent volumes.

Table 5. Comparison between methods used to determine Npx in human urine.

\begin{tabular}{|c|c|c|c|c|c|c|}
\hline $\begin{array}{c}\text { Sample Preparation } \\
\text { Method }\end{array}$ & $\begin{array}{l}\text { Detection } \\
\text { System }\end{array}$ & $\operatorname{LOD}\left(\mu \mathrm{g} \mathrm{L}^{-1}\right)$ & RSD (\%) & $\begin{array}{c}\text { Sample Volume } \\
(\mathrm{mL})\end{array}$ & $\begin{array}{l}\text { Reconstitution } \\
\text { Volume (mL) }\end{array}$ & Reference \\
\hline MMOF-SPME $^{\text {a }}$ & HPLC-UV & 0.03 & $<4.7$ & 5.0 & 2.0 & [40] \\
\hline LDH-PS- $\mu$ SPE ${ }^{b}$ & HPLC-UV & 5.0 & $<7.4$ & 0.25 & 0.2 & [8] \\
\hline MFA-SPE $^{c}$ & HPLC-UV & 2.0 & $<6.7$ & 50.0 & 5.0 & [41] \\
\hline MIP-SPE ${ }^{d}$ & FLD & 2.0 & $<1.0$ & $40.0-100.0$ & 2.0 & [3] \\
\hline MSPE & HPLC-FLD & 0.02 & $<5.2$ & 1.0 & 0.5 & This work \\
\hline
\end{tabular}

${ }^{a}$ Magnetic metal organic frameworks nanocomposite fiber solid-phase microextraction; ${ }^{b}$ Micro-solid phase extraction by packed sorbent layered double hydroxide; ${ }^{c}$ Magnetic field assisted $\mu$-solid phase extraction;

d Molecularly imprinted polymer solid-phase extraction. 


\section{Materials and Methods}

\subsection{Chemicals}

Ethylene glycol dimethacrylate (EGDMA), (S)-(+)-6-Methoxy- $\alpha$-methyl-2-naphthaleneacetic acid (Npx), methyl acrylate (MA), methanol HPLC grade, 4-vynilpiridine (4-VP), and 1-naphtaleneacetic acid (internal standard, IS) were obtained from Sigma Aldrich (St Louis, MO, USA). Sodium chloride, ammonium persulfate, ferrous sulfate heptahydrate, sodium hydroxide, polysorbate 80 (Tween 80), acetic acid and hydrochloric acid were purchased from J.T. Baker (Phillipsburg, NJ, USA). All the solutions were prepared using deionized water from Milli-Q system with a resistivity no less than 18.0 M $\Omega$ (Millipore, Bedford, MA, USA).

\subsection{Equipment}

The characterization of the synthesized solids was made by using an INEL Equinox 2000, diffractometer with $\operatorname{CoK} \alpha 1$ radiation $(\lambda=1.7890100 \AA)$. The patterns were recorded in a $2 \theta$ interval of $20-70^{\circ}$ with increments of $0.02^{\circ}(2 \theta)$. The $\mathrm{pH}$ measurements were performed with a $\mathrm{pH}$ meter Oakton pH510 Series (Vernon Hills, IL, USA). For the infrared spectroscopy study, a Perkin Elmer spectrometer model GX (Waltham, MA. USA) was used in a range of $4000-400 \mathrm{~cm}^{-1}$, the samples were prepared and analyzed in $\mathrm{KBr}$.

Npx analysis was performed by HPLC using an Agilent Technologies 1260 Infinity (DE, Germany) equipped with an Agilent Zorbax ODS Analytical $4.6 \times 250 \mathrm{~mm}, 5-\mu \mathrm{m}$ column. The analytic signals were detected using a fluorescence detector set at excitation and emission wavelengths of 271 and $356 \mathrm{~nm}$, respectively. The mobile phase is comprised of $70 \%$ methanol and $30 \%$ of acetic acid aqueous solution at $1 \%(v / v)$ with a flow rate of $0.8 \mathrm{~mL} \mathrm{~min}^{-1}$. The injection volume was $20.0 \mu \mathrm{L}$. The equipment is controlled by the software Agilent OpenLAB.

\subsection{Synthesis of Magnetic Solids}

Three magnetic solids (A, B and C) were synthesized in two steps using the proportions shown in Table 6. The first step consists in the synthesis of the magnetite core from $\mathrm{FeSO}_{4} \cdot 7 \mathrm{H}_{2} \mathrm{O}$. $\mathrm{NaOH}$ was added to $\mathrm{Fe}$ (II) solution to reach a $\mathrm{pH}$ value of $10.0 \pm 0.2$ in presence of an air current, the ferrous precipitate was partially oxidized and separated from the liquid phase placing a magnet on the external part of the flask [42]. The solid was rinsed $(25.0 \mathrm{~mL} \times 5)$ with deionized water and the magnetic phase obtained was dispersed in $100 \mathrm{~mL}$ of Tween $80(0.5 \% \mathrm{w} / \mathrm{v})$ and it was stirred for $10 \mathrm{~min}$ at $75{ }^{\circ} \mathrm{C}$.

Table 6. Molar ratio of the synthesized magnetic solids.

\begin{tabular}{ccccc}
\hline Solid & $\begin{array}{c}\text { Magnetite } \\
(\mathbf{m m o L})\end{array}$ & $\begin{array}{c}\text { 4-VP } \\
(\mathbf{m m o L})\end{array}$ & $\begin{array}{c}\text { MA } \\
(\mathbf{m m o L})\end{array}$ & $\begin{array}{c}\text { EGDMA } \\
(\mathbf{m m o L})\end{array}$ \\
\hline A & 3.0 & 0.3 & 0.3 & 5.0 \\
B & 6.0 & 0.3 & 0.3 & 5.0 \\
C & 12.0 & 0.3 & 0.3 & 5.0 \\
\hline
\end{tabular}

The extracting phase was synthesized by emulsion polymerization adding 4-VP as functional monomer, EGDMA as crosslinker and MA. The monomers were selected because of solubility of $\mathrm{P} 4-\mathrm{VP}$ in water at low $\mathrm{pH}$ values, in order to protect the magnetic core and minimize loss of extracting phase, it was included MA and EGDMA to promote the synthesis of a hydrophobic crosslinked co-polymer [43]. The monomers were added to the magnetite suspension in the following order: MA, EGDMA and 4-VP. Once added, $5.0 \mathrm{~mL}$ of a solution of ammonium persulfate $(1.4 \% w / v)$ is added and the mixture was stirred for an hour. The solid obtained was separated magnetically, rinsed with deionized water and dried at $60{ }^{\circ} \mathrm{C}$ for $12 \mathrm{~h}$. The dry solids were pulverized in agate mortar and stored in dark until their use. 


\subsection{Characterization of the Solid}

The number of active sites of each magnetic solid was determined using an acid titration. $50.0 \mathrm{mg}$ of the magnetic solid were mixed with $10.0 \mathrm{~mL}$ of $\mathrm{NaOH}(0.01 \mathrm{M})$, the suspension was titrated then using $\mathrm{HCl} 0.01 \mathrm{M}$ to achieve a $\mathrm{pH}$ value of 3.0, potentiometric recording showed two equivalence points. Active sited were determined by difference between equivalence points, and the value is expressed as $\mathrm{mmol}_{\mathrm{HCl}} \mathrm{kg}^{-1}$.

The adsorption capability of each solid was evaluated using adsorption isothermals at $\mathrm{pH}=2.0$ (adjusted with $\mathrm{HCl} 0.1 \mathrm{M}$ ). Under these conditions $\mathrm{Npx}$ is retained after reaction of the carboxylic group with P4-VP. Adsorption experiments were performed by mixing, $10.0 \mathrm{mg}$ of each solid and $2.0 \mathrm{~mL}$ with $\mathrm{Npx}$ aqueous solution (20.0-100.0 $\mathrm{mg} \mathrm{L}^{-1}$ ) in polypropylene tubes. The solutions were stirred during $30 \mathrm{~min}$, the solid was magnetically isolated and the liquid phase was analyzed by HPLC.

\subsection{Sample Analysis}

Four urine samples $(10 \mathrm{~mL})$ from healthy individuals were stored at $-20^{\circ} \mathrm{C}$ until their analysis. The proposed methodology (Figure 6) involves the following steps. a) $10.0 \mathrm{mg}$ of the magnetic solid was activated with $1.0 \mathrm{~mL}$ of methanol, it is washed twice with $1.0 \mathrm{~mL}$ of deionized water; b) $1.0 \mathrm{~mL}$ of the sample is diluted to $10.0 \mathrm{~mL}$ with a solution composed of $\mathrm{HCl}\left(1 \times 10^{-3} \mathrm{M}\right), \mathrm{NaCl}(1.0 \mathrm{M})$ and the internal standard $\left.\left(50 \mu \mathrm{g} \mathrm{L}^{-1}\right) ; \mathrm{c}\right)$ the sample diluted was added to the activated magnetic solid and the mixture was mechanically stirred for $30 \mathrm{~min}$; d) magnetic phase is separated using a neodymium magnet reserving the solid phase; e) the solid phase was washed with $1.0 \mathrm{~mL}$ of deionized water followed by $3.0 \mathrm{~mL}$ of methanol to eluted the analyte; f) the phases were magnetically separated and the liquid phase was evaporated, the residue was reconstituted in $0.5 \mathrm{~mL}$ of methanol and analyzed by HPLC.

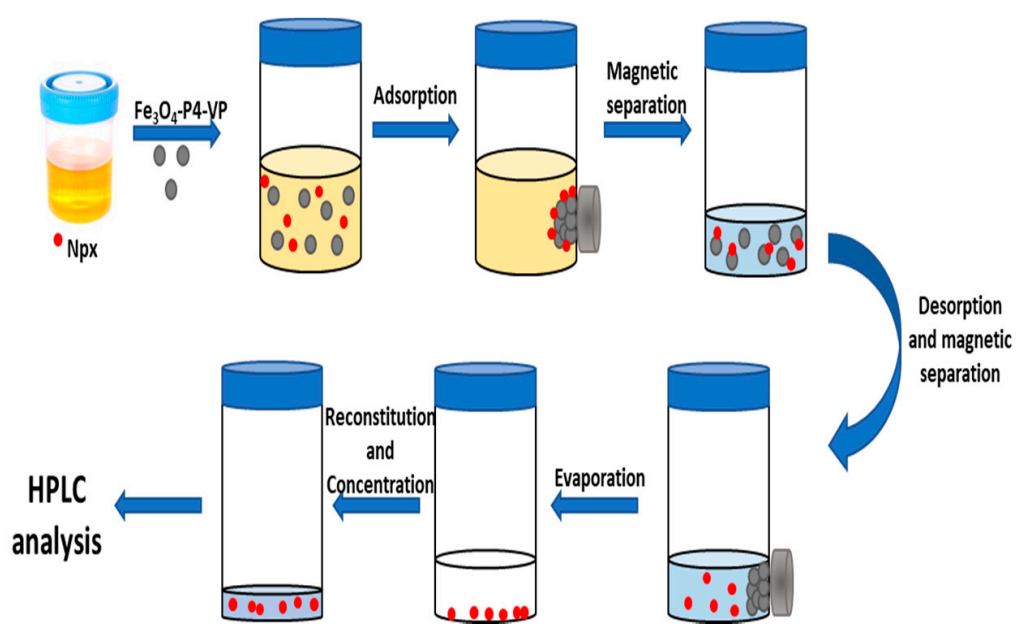

Figure 6. Schematic procedure for the isolation of several Npx from urine samples by magnetic solid phase extraction (MSPE).

\section{Conclusions}

In this work, solids based on magnetite and P4-VP were synthesized for their application in the separation of $\mathrm{Npx}$ in urine samples. The increment in the concentration of magnetite favors the disposition of the pyridine groups, improving the solid-analyte affinity. The methodology developed for the determination of Npx is robust, simple and fast, it uses small sample and solvent volumes, in addition to be a promising technique for the analysis of Npx in complex samples. The achieved detection limits are competitive with the ones described in other described methodologies. 
Author Contributions: Conceptualization, A.P.-A. and I.S.I.; methodology, K.A.E.-L. and A.C.H.; formal analysis, J.A.R. and E.B.; writing — original draft preparation, K.A.E.-L.; writing-review and editing, J.A.R. All authors have read and agreed to the published version of the manuscript.

Funding: This research was funded by PROFOCIE-UAEH-2019.

Conflicts of Interest: The authors declare no conflict of interest.

\section{References}

1. Santini, A.O.; Oliveira, J.E.D.; Pezza, H.R.; Pezza, L. A novel potentiometric naproxenate ion sensor immobilized in a graphite matrix for determination of naproxen in pharmaceuticals. J. Braz. Chem. Soc. 2006, 17, 785-791. [CrossRef]

2. Adhoum, N.; Monser, L.; Toumi, M.; Boujlel, K. Determination of naproxen in pharmaceuticals by differential pulse voltammetry at a platinum electrode. Anal. Chim. Acta 2003, 495, 69-75. [CrossRef]

3. Madrakian, T.; Ahmadi, M.; Afkhami, A.; Soleimani, M. Selective solid-phase extraction of naproxen drug from human urine samples using molecularly imprinted polymer-coated magnetic multi-walled carbon nanotubes prior to its spectrofluorometric determination. Analyst 2013, 138, 4542-4549. [CrossRef] [PubMed]

4. Haque, T.; Talukder, M.M.U.; Laila, S.; Fatema, K.; Kabir, A.K.L. Simultaneous estimation of naproxen and ranitidine $\mathrm{HCl}$ by using UV spectrophotometer. Stamford J. Pharm. Sci. 2008, 1, 18-24. [CrossRef]

5. Sebők, Á.; Vasanits-Zsigrai, A.; Palkó, G.; Záray, G.; Molnár-Perl, I. Identification and quantification of ibuprofen, naproxen, ketoprofen and diclofenac present in waste-waters, as their trimethylsilyl derivatives, by gas chromatography mass spectrometry. Talanta 2008, 76, 642-650. [CrossRef] [PubMed]

6. Hu, Y.; Song, C.; Liao, J.; Huang, Z.; Li, G. Water stable metal-organic framework packed microcolumn for online sorptive extraction and direct analysis of naproxen and its metabolite from urine sample. J. Chromatogr. A 2013, 1294, 17-24. [CrossRef]

7. Phillips, T.M.; Wellner, E.F. Measurement of naproxen in human plasma by chip-based immunoaffinity capillary electrophoresis. Biomed. Chromatogr. 2006, 20, 662-667. [CrossRef]

8. Seidi, S.; Sanàti, S.E. Nickel-iron layered double hydroxide nanostructures for micro solid phase extraction of nonsteroidal anti-inflammatory drugs, followed by quantitation by HPLC-UV. Microchim. Acta 2019, 186, 297. [CrossRef]

9. Wang, J.Q.; Zheng, B.G.; Zhang, J.B.; Zheng, Z. Degradation of the emerging contaminant naproxen in aqueous solutions by dielectric barrier discharge. Asian J. Chem. 2013, 25, 3595-3600. [CrossRef]

10. Santos, J.L.; Aparicio, I.; Alonso, E.; Callejón, M. Simultaneous determination of pharmaceutically active compounds in wastewater samples by solid phase extraction and high-performance liquid chromatography with diode array and fluorescence detectors. Anal. Chim. Acta 2005, 550, 116-122. [CrossRef]

11. Jim, T.Y.; Bisceglia, K.J.; Bouwer, E.J.; Roberts, A.L.; Coelhan, M. Determination of pharmaceuticals and antiseptics in water by solid-phase extraction and gas chromatography/mass spectrometry: Analysis via pentafluorobenzylation and stable isotope dilution. Anal. Bioanal. Chem. 2012, 403, 583-591. [CrossRef]

12. Duan, C.; Shen, Z.; Wu, D.; Guan, Y. Recent developments in solid-phase microextraction for on-site sampling and sample preparation. TrAC, Trends Anal. Chem. 2011, 30, 1568-1574. [CrossRef]

13. Aqda, T.G.; Behkami, S.; Bagheri, H. Porous eco-friendly fibers for on-line micro solid-phase extraction of nonsteroidal anti-inflammatory drugs from urine and plasma samples. J. Chromatogr. A 2018, 1574, 18-26. [CrossRef] [PubMed]

14. Ghorbani, M.; Chamsaz, M.; Rounaghi, G.H. Ultrasound-assisted magnetic dispersive solid-phase microextraction: A novel approach for the rapid and efficient microextraction of naproxen and ibuprofen employing experimental design with high-performance liquid chromatography. J. Sep. Sci. 2016, 39, 1082-1089. [CrossRef] [PubMed]

15. Ghorbani, M.; Aghamohammadhasan, M.; Shams, A.; Tajfirooz, F.; Pourhassan, R.; Khosravi, S.R.B.; Jampour, A. Ultrasonic assisted magnetic dispersive solid phase microextraction for preconcentration of two nonsteroidal anti-inflammatory drugs in real water, biological and milk samples employing an experimental design. Microchem. J. 2019, 145, 1026-1035. [CrossRef]

16. Andrade-Eiroa, A.; Canle, M.; Leroy-Cancellieri, V.; Cerdà, V. Solid-phase extraction of organic compounds: A critical review (Part I). TrAC, Trends Anal. Chem. 2016, 80, 641-654. [CrossRef] 
17. Khezeli, T.; Daneshfar, A. Development of dispersive micro-solid phase extraction based on micro and nano sorbents. TrAC Trends Anal. Chem. 2017, 89, 99-118. [CrossRef]

18. Asgharinezhad, A.A.; Ebrahimzadeh, H. Poly (2-aminobenzothiazole)-coated graphene oxide/magnetite nanoparticles composite as an efficient sorbent for determination of non-steroidal anti-inflammatory drugs in urine sample. J. Chromatogr. A 2016, 1435, 18-29. [CrossRef]

19. Li, G.; Deng, R.; Peng, G.; Yang, C.; He, Q.; Lu, Y.; Shi, H. Magnetic solid-phase extraction for the analysis of bisphenol A, naproxen and triclosan in wastewater samples. Water Sci. Technol. 2018, 77, 2220-2227. [CrossRef]

20. Abujaber, F.; Zougagh, M.; Jodeh, S.; Ríos, Á.; Bernardo, F.J.G.; Martín-Doimeadios, R.C.R. Magnetic cellulose nanoparticles coated with ionic liquid as a new material for the simple and fast monitoring of emerging pollutants in waters by magnetic solid phase extraction. Microchem. J. 2018, 137, 490-495. [CrossRef]

21. Mohammadi Nodeh, M.K.; Radfard, M.; Zardari, L.A.; Rashidi Nodeh, H. Enhanced removal of naproxen from wastewater using silica magnetic nanoparticles decorated onto graphene oxide; parametric and equilibrium study. Sep. Sci. Technol. 2018, 53, 2476-2485. [CrossRef]

22. Aguilar-Arteaga, K.; Rodriguez, J.A.; Miranda, J.M.; Medina, J.; Barrado, E. Determination of non-steroidal anti-inflammatory drugs in wastewaters by magnetic matrix solid phase dispersion-HPLC. Talanta 2010, 80, 1152-1157. [CrossRef] [PubMed]

23. Rafighi, P.; Yaftian, M.R.; Haghighi, B. Magnetic nanofibrous polyaniline nanocomposite for solid-phase extraction of naproxen from biological samples prior to its spectrofluorimetric determination. J. Iran. Chem. Soc. 2018, 15, 1209-1221. [CrossRef]

24. Barrado, E.; Rodríguez, J.A. Extraction. Magnetic Materials in Separation Science. Encycl Anal. Sci. 2019, 3, 63-66. [CrossRef]

25. Kempe, M.; Mosbach, K. Direct resolution of naproxen on a non-covalently molecularly imprinted chiral stationary phase. J. Chromatogr. A 1994, 664, 276-279. [CrossRef]

26. Li, Y.; Wang, Y.; He, L.; Meng, L.; Lu, H.; Li, X. Preparation of poly(4-vinylpyridine)-functionalized magnetic Al-MOF for the removal of naproxen from aqueous solution. J. Hazard. Mater. 2020, 383, 121144. [CrossRef] [PubMed]

27. Liu, X.M.; Kim, J.K. Solvothermal synthesis and magnetic properties of magnetite nanoplatelets. Mater. Lett. 2009, 63, 428-430. [CrossRef]

28. Bagheri, A.R.; Ghaedi, M.; Asfaram, A.; Bazrafshan, A.A.; Jannesar, R. Comparative study on ultrasonic assisted adsorption of dyes from single system onto $\mathrm{Fe} 3 \mathrm{O} 4$ magnetite nanoparticles loaded on activated carbon: Experimental design methodology. Ultrason. Sonochem. 2017, 34, 294-304. [CrossRef]

29. Sahiner, N.; Ilgin, P. Multiresponsive polymeric particles with tunable morphology and properties based on acrylonitrile (AN) and 4-vinylpyridine (4-VP). Polymer 2010, 51, 3156-3163. [CrossRef]

30. Ibarra, I.S.; Rodriguez, J.A.; Miranda, J.M.; Vega, M.; Barrado, E. Magnetic solid phase extraction based on phenyl silica adsorbent for the determination of tetracyclines in milk samples by capillary electrophoresis. J. Chromatogr. A 2011, 1218, 2196-2202. [CrossRef]

31. Illés, E.; Tombácz, E. The effect of humic acid adsorption on $\mathrm{pH}$-dependent surface charging and aggregation of magnetite nanoparticles. J. Colloid Interface Sci. 2006, 295, 115-123. [CrossRef] [PubMed]

32. Rutnakornpituk, B.; Wichai, U.; Vilaivan, T.; Rutnakornpituk, M. Surface-initiated atom transfer radical polymerization of poly (4-vinylpyridine) from magnetite nanoparticle. J. Nanopart. Res. 2011, 13, 6847-6857. [CrossRef]

33. Rodriguez, J.A.; Espinosa, J.; Aguilar-Arteaga, K.; Ibarra, I.S.; Miranda, J.M. Determination of tetracyclines in milk samples by magnetic solid phase extraction flow injection analysis. Microchim. Acta 2010, 171, 407-413. [CrossRef]

34. Aresta, A.; Palmisano, F.; Zambonin, C.G. Determination of naproxen in human urine by solid-phase microextraction coupled to liquid chromatography. J. Pharm. Biomed. Anal. 2005, 39, 643-647. [CrossRef]

35. Sarafraz-Yazdi, A.; Amiri, A.; Rounaghi, G.; Eshtiagh-Hosseini, H. Determination of non-steroidal anti-inflammatory drugs in water samples by solid-phase microextraction based sol-gel technique using poly (ethylene glycol) grafted multi-walled carbon nanotubes coated fiber. Anal. Chim. Acta 2012, 720, 134-141. [CrossRef] 
36. Ayazi, Z.; Matin, A.A. Development of carbon nanotube-polyamide nanocomposite-based stir bar sorptive extraction coupled to HPLC-UV applying response surface methodology for the analysis of bisphenol a in aqueous samples. J. Chromatogr. Sci. 2016, 54, 1841-1850. [CrossRef]

37. Nagai, K.; Shibata, T.; Shinkura, S.; Ohnishi, A. Poly (4-vinylpyridine) based novel stationary phase investigated under supercritical fluid chromatography conditions. J. Chromatogr. A 2018, 1572, 119-127. [CrossRef]

38. Mafra, G.; Spudeit, D.; Brognoli, R.; Merib, J.; Carasek, E. Expanding the applicability of cork as extraction phase for disposable pipette extraction in multiresidue analysis of pharmaceuticals in urine samples. J. Chromatogr. B 2018, 1102, 159-166. [CrossRef]

39. Food and Drug Administration. Q2 (R1) Validation of Analytical Procedures: Text and Methodology. Available online: https://www.fda.gov/regulatory-information/search-fda-guidance-documents/q2-r1validation-analytical-procedures-text-and-methodology (accessed on 15 June 2020).

40. Caro, E.; Marcé, R.M.; Cormack, P.A.; Sherrington, D.C.; Borrull, F. A new molecularly imprinted polymer for the selective extraction of naproxen from urine samples by solid-phase extraction. J. Chromatogr. B 2004, 813, 137-143. [CrossRef]

41. Bagheri, H.; Khanipour, P.; Asgari, S. Magnetic field assisted $\mu$-solid phase extraction of anti-inflammatory and loop diuretic drugs by modified polybutylene terephthalate nanofibers. Anal. Chim. Acta 2016, 934, 88-97. [CrossRef]

42. Ibarra, I.S.; Miranda, J.M.; Rodriguez, J.A.; Nebot, C.; Cepeda, A. Magnetic solid phase extraction followed by high-performance liquid chromatography for the determination of sulphonamides in milk samples. Food Chem. 2014, 157, 511-517. [CrossRef] [PubMed]

43. Hamulić, D.; Rodič, P.; Poberžnik, M.; Jereb, M.; Kovač, J.; Milošev, I. The Effect of the Methyl and Ethyl Group of the Acrylate Precursor in Hybrid Silane Coatings Used for Corrosion Protection of Aluminium Alloy 7075-T6. Coatings 2020, 10, 172. [CrossRef]

Sample Availability: Samples of the solids compounds A, B and C are available from the authors.

(C) 2020 by the authors. Licensee MDPI, Basel, Switzerland. This article is an open access article distributed under the terms and conditions of the Creative Commons Attribution (CC BY) license (http://creativecommons.org/licenses/by/4.0/). 